\title{
Pengejawantahan Pendekatan Storytelling dalam Pemahaman Membangun Diagram Alir Data
}

\author{
Herlinda $^{1}$, Randi Ramliyana ${ }^{2}$, Erlin Windia Ambarsari*3 \\ 1,2,3 Program Studi Teknik Informatika, Universitas Indraprasta PGRI \\ herlindasaid72@gmail.com ${ }^{1}$, randi.ramliyana@gmail.com ${ }^{2}$, erlinunindra@gmail.com*3
}

(Received: 7 Oktober 2021 / Accepted: 17 November 2021 / Published Online: 20 Desember 2021)

\begin{abstract}
Abstrak
Perangkat lunak dibuat melalui beberapa tahapan system development life cycle (SDLC). Salah satu tahapan SDLC yang paling penting adalah mendesain sistem. Pemodelan yang dapat digunakan untuk mendesain sistem adalah Diagram Alir Data (DAD). Tujuan penelitian ini dibuat agar orang-orang yang membaca diagram lebih mudah untuk menginterpretasikan dengan penyusunan DAD yang sistematis sehingga perangkat lunak dibangun sesuai dengan rancangan DAD. Pendekatan yang digunakan adalah Storytelling yang merujuk pada metode kualitatif dalam pembuatan pola kalimat. Selanjutnya, dibuat pola DAD sebagai acuan rancangan. Penelitian ini menyimulasikan dua buah kasus untuk mewakili penelitian terdahulu yang mempunyai konsep yang sama. Hasil yang didapatkan pada penelitian ini adalah terdapatnya dua perbedaan yang signifikan. Kasus 1 mengacu pada aktivitas pengguna sistem dan kasus 2 merujuk ke kinerja perangkat lunak. Pada hasil olahan dibuat dari pola kalimat ke pola DAD, storytelling kasus 1 lebih konsisten dan mudah dibuat perancangannya karena mengacu pada konsep dasar input-proses-output. Sebaliknya, kasus 2 banyak mengaitkan simbol proses ke proses sehingga pembuatan rancangan DAD semakin kompleks. Sebagai kesimpulan, kasus 2 berguna untuk elisitasi kebutuhan dan kasus 1 merujuk pada proses bisnis.
\end{abstract}

Kata kunci: DAD, Pola Kalimat, Storytelling

\begin{abstract}
Throughout the System Development Life Cycle (SDLC), establishment the software through various phases. System design is one of the most crucial aspects of the SDLC. The Data Flow Diagram (DFD) is a model to build the system. The purpose of the research was to make it easier for people to comprehend the diagram by carefully preparing DFD, then it created software according to the DFD design. Storytelling is the method employed, and it pertains to qualitative ways for creating language patterns. As a design reference, it needs to make the DFD pattern subsequently. The research mimics two scenarios to reflect previous research on the same principle. According to the findings of this study, there are two significant disparities. The first scenario concerns system user activity, whereas the second concerns software performance. Therefore, it corresponds to the core notion of input-processoutput; narrative scenario 1 is more consistent and easier to design in the processed results created from sentence patterns to DFD patterns. Scenario 2, on the other hand, connects many process symbols to processes, complicating the DFD design. Finally, scenario 2 is beneficial for requirement's elicitation, whereas scenario 1 applies to business procedures.
\end{abstract}

Keywords: DFD, Sentence Pattern, Storytelling

\section{PENDAHULUAN}

Pembangunan perangkat lunak dapat diwujudkan dengan melalui beberapa tahap prosedural System Development Life Cycle (SDLC), salah satu tahapan yang paling penting dari SDLC adalah mendesain system (Muntohar, 2020; Sakti et al., 2020) . Tujuan desain sistem untuk memvisualkan bagaimana sistem perangkat lunak dibentuk baik proyeksi secara umum maupun terinci. Beberapa pendekatan pemodelan yang sering digunakan dalam 
mendesain sistem antara lain flowchart, Diagram Alir Data (DAD), dan Unified Modelling Language (UML).

Walaupun DAD merupakan pemodelan klasik yang dikemukakan Larry Constantine pada tahun 1970-an (Aleryani, 2016), beberapa perusahaan dan insitusi akademik masih menggunakan model tersebut. Pemodelan DAD juga menjadi alat analisis kerja sistem sehingga kebutuhan pengguna perangkat lunak dapat dipenuhi. Oleh karena itu, DAD yang dibuat lebih mudah dipahami proses atau aliran sistem dibandingkan menganalisis dengan mendeskripsikan kata-kata (Hathaway \& Hathaway, 2015). Walaupun DAD disajikan dengan notasi Gane-Sarson atau Yourdon-Demarco (Soufitri, 2019), pendesain masih mengalami kesulitan dalam merangkai notasi. Kesalahan yang sering terjadi pada saat merancang DAD adalah blackhole, miracle, dan tidak lengkapnya input-output. Kendala yang lain adalah kesalahan interpretasi yang berakibat terjadi kegagalan pemenuhan kebutuhan sistem.

Oleh sebab itu, penelitian ini mengacu pada pendekatan storytelling (mendongeng) untuk mengatasi kesalahan perancangan. Teknik storytelling sudah diterapkan pada dunia pendidikan terutama untuk meningkatkan keterampilan berbicara (Pratiwi, 2016) dan keterampilan membaca (Hidayat et al., 2019). Penerapan tersebut dapat didasari oleh (Gürsoy, 2021), bahwa storytelling dapat berupa narasi yang berisi pengalaman, tradisional, atau budaya leluhur dengan menggunakan bahasa, vokalisasi, dan gerak-isyarat untuk menyimulasi adegan peristiwa. Storytelling dapat digunakan sebagai perangkat pengajaran dalam bidang pendidikan guru, sekolah tinggi, pendidikan anak usia dini, dan pendidikan keperawatan (Satriani, 2019).

Namun, bukan hanya dalam pengajaran saja, melainkan juga storytelling diperluas pada bidang-bidang lainnya, seperti perancang busana (Kim \& Hartanto, 2020), bisnis (Lundqvist et al., 2013), dan data. Pada artikel (Matei \& Hunter, 2021) disimpulkan bahwa data storytelling menceritakan masalah korelasi dari sebab-akibat dengan tidak mengabaikan fakta. Penyajian data storytelling dapat berbeda-beda di kalangan sesama para ahli dan masyarakat awam. Penyajian dapat menggunakan perantara media dalam bentuk visualisasi. Oleh karena itu, data storytelling dituangkan ke dalam visualisasi data berupa diagram, peta, atau grafik (Ambarsari \& Herlinda, 2020; Knaflic, 2015)

Storytelling pada DAD dapat ditemukan pada beberapa artikel. Akan tetapi, penyusunan pada diagram masih belum tepat, yakni (Afuan et al., 2021) di mana kekurangan rancangan DAD pada penelitian tersebut terdapat input-output tidak lengkap terutama arus data yang menghubungkan entitas nasabah dengan membandingkan antara diagram konteks dan nol. Hasilnya interpretasi menjadi tidak sama (unbalance). Selain itu, arus data pada entitas admin terdapat empat arus info laporan pada diagram nol, sedangkan arus tersebut tidak ada di diagram konteks. Temuan yang lain terdapatnya nama arus yang sama seperti data login yang bersumber dari entitas nasabah, admin, dan manager sehingga arus mana yang tersimpan pada data storage menjadi tidak jelas. Selanjutnya, perangkat lunak dalam penelitian ini berbeda dengan DAD yang dirancang, adanya grafik monitoring yang tidak digambarkan dalam DAD. (Reforma et al., 2021) terdapat penambahan arus pada diagram nol yaitu entitas guru dan tata usaha, entitas kelas dan mata pelajaran pada diagram konteks yang seharusnya merupakan data storage di diagram nol. Kemudian, terjadi miracle menuju data storage kelas dan mata pelajaran. (Wibowo et al., 2014) terjadi kesalahan notasi yaitu mengaitkan entitas dengan entitas. Ketiga penelitian tersebut sudah melanggar aturan penyusunan DAD, sedangkan penelitiannya (Rohimah \& Kustian, 2021) storytelling sudah terbaca. Namun, penamaan arus data dan proses perlu diluruskan.

Beberapa kasus yang ditemukan dari beberapa penelitian tersebut maka teknik storytelling mesti mengikuti kaidah kalimat yang baik agar dipahami oleh orang yang membacanya. Oleh karena itu, penelitian ini mengejawantahkan pendekatan storytelling ke dalam DAD sesuai dengan pola kalimat bahasa Indonesia. Selanjutnya, pola kalimat tersebut membentuk pola DAD sehingga berimbang dengan aturan penyusunan DAD. Tujuan 
penelitian ini dibuat agar orang-orang yang membaca diagram lebih mudah untuk menginterpretasikan proses atau aliran data yang berjalan dalam sistem dengan penyusunan DAD yang sistematis sehingga perangkat lunak dibangun sudah sesuai dengan rancangan DAD.

\section{METODE}

Pendekatan yang digunakan pada penelitian ini adalah kualitatif yang memanifestasikan data deskriptif berupa data tertulis dan lisan. Dilakukan dengan dua tahapan secara berurutan, yakni pengumpulan data; analisis data (Septianingtias, 2015). Pada tahap pengumpulan data dilakukan dengan metode catat dengan mencatat kalimat yang ada di dalam DAD. Pada tahap data, penelitian ini menggunakan metode agih, yaitu metode analisis yang unsur penentunya berada di dalam bahasa itu sendiri. Prinsip dasar dalam metode agih ini adalah Bagi Unsur Langsung (BUL) dengan menentukan bagian-bagian fungsional suatu konstruksi menjadi beberapa unsur. Teknik analisis data dipenuhi dengan memilah kalimat dan menganalisisnya berdasarkan pola kalimat (Kusuma, 2007). Sementara itu, sumber data penelitian ini adalah kalimat-kalimat yang terdapat dalam DAD.

Teknik analisis data yang digunakan pada penelitian ini adalah pola penyusunan kalimat. Secara sintaksis, kalimat dapat dicermati berdasarkan unsur fungsi, kategori, dan peran. Pola kalimat dasar merujuk pada unsur fungsi kalimat, yaitu subjek, predikat, objek, pelengkap, dan keterangan. Pola kalimat dasar memiliki enam pola (Moeliono et al., 2017) dapat diamati pada tabel 1 .

Tabel 1. Pola Kalimat Dasar

\begin{tabular}{cccccc}
\hline $\begin{array}{c}\text { Pola } \\
\text { Kalimat }\end{array}$ & Subjek & Predikat & Objek & Pelengkap & Keterangan \\
\hline S-P & Mereka & sedang minum. & & & \\
S-P-O & Mereka & sedang meminum & susu. & & \\
S-P-Pel & Mereka & sedang minum & & susu. & \\
S-P-Ket & Mereka & sedang minum & & & di kantin. \\
S-P-O-Pel & Mereka & sedang & adik & susu. & \\
& meminumkan & & & di kantin. \\
\hline
\end{tabular}

Selain itu, penganalisisan dalam penelitian ini akan membutuhkan rumus dalam mencari pola kalimat tersebut yang disajikan pada tabel 2. Pola kalimat tersebut dianalisis berdasarkan narasi pada kasus, kemudian setiap kata dan kalimat akan diinterpretasi ke dalam simbol DAD dengan memisahkan kata mengikuti rumus unsur pola kalimat. Oleh karena itu, penelitian ini dilakukan simulasi pada diagram nol sebagai contoh pengerjaan dengan mengabaikan data storage dan pengelompokkan proses. Alasan pemilihan diagram tersebut karena pemahaman storytelling akan lebih mudah dilihat alurnya. Langkah-langkah pengerjaan storytelling dilakukan sebagai berikut.

1. Menyusun kalimat yang menjadi dasar storytelling. Kalimat ini dikumpulkan dan dintepretasikan untuk menemukan pola kalimat.

2. Pola kalimat yang sudah ditandai, kemudian disusun berdasarkan simbol DAD yang terdiri dari entitas, proses, dan arus data. Selanjutnya, pola kalimat membentuk pola DAD. Simbol DAD merujuk pada Yourdon-Demarco.

3. Setiap penamaan pada simbol DAD berdasarkan rumus unsur pola kalimat. Khusus simbol proses menggunakan imbuhan pe-an, berdasarkan dari Tata Bahasa Baku Bahasa Indonesia (TBBBI). Makna yang ditimbulkan dari alomorf pe-an adalah menyatakan sebuah proses, cara, pembuatan me-. 
Contoh:

Pe- + makam + -an = pemakaman artinya proses, cara, pembuatan memakamkan.

$\mathrm{Pe}-+$ data +- an $=$ pedataan artinya proses, cara, pembuatan mendata.

$\mathrm{Pe}-+$ isi +- an $=$ pengisian artinya proses, cara pembuatan mengisi.

Pada penulisan pe-an tidak perlu diawali dengan kata proses, cara, dan perbuatan.

Tabel 2. Rumus Unsur Pola Kalimat

\begin{tabular}{|c|c|c|c|c|c|}
\hline & Subjek (S) & Predikat (P) & Objek (O) & $\begin{array}{l}\text { Pelengkap } \\
\text { (Pel) }\end{array}$ & $\begin{array}{c}\text { Keterangan } \\
\text { (Ket) }\end{array}$ \\
\hline Definisi & $\begin{array}{c}\text { Pokok } \\
\text { pembahasan/ } \\
\text { Apa yang } \\
\text { dibahas }\end{array}$ & $\begin{array}{c}\text { Yang } \\
\text { dilakukan } \\
\text { subjek }\end{array}$ & $\begin{array}{c}\text { Nomina yang } \\
\text { melengkapi } \\
\text { verba transitif }\end{array}$ & $\begin{array}{c}\text { Unsur kalimat } \\
\text { yang } \\
\text { melengkapi } \\
\text { predikat } \\
\text { verbal }\end{array}$ & $\begin{array}{c}\text { Kata/kelomp } \\
\text { ok kata yang } \\
\text { menerangkan } \\
\text { kata/bagian } \\
\text { kalimat lain }\end{array}$ \\
\hline Jenis kata & $\begin{array}{c}\mathrm{N}, \mathrm{FN}, \mathrm{V} \\
\mathrm{Adj}, \mathrm{Nu}\end{array}$ & $\begin{array}{c}\text { N, FN, V, } \\
\text { FV, Adj, } \\
\text { FAdj, Nu, } \\
\text { FNu }\end{array}$ & $\mathrm{N}, \mathrm{FN}$ & $\mathrm{N}, \mathrm{FN}$ & FD \\
\hline Imbuhan & $\begin{array}{l}\text { Kata dasar, } \\
\text { pe-an, per-an, } \\
\text { ke-an, -an, } \\
\text { ber-, pe- }\end{array}$ & $\begin{array}{l}\text { Kata dasar, } \\
\text { me-, di-, ber-, } \\
\text { me-kan, me-i, } \\
\text { ke-, ter-, } \\
\text { adalah, } \\
\text { merupakan, } \\
\text { menjadi, } \\
\text { ialah }\end{array}$ & $\begin{array}{c}\text { Jika Predikat } \\
\text { berimbuhan } \\
\text { me-, me-kan, } \\
\text { me-i, (aktif) } \\
\text { dapat diubah } \\
\text { menjadi di- } \\
\text { (pasif) }\end{array}$ & $\begin{array}{c}\text { Jika predikat } \\
\text { berimbuhan } \\
\text { ber-, me- } \\
\text { (tidak dapat } \\
\text { diubah pasif), } \\
\text { ter-, ke-, } \\
\text { adalah, ialah, } \\
\text { merupakan, } \\
\text { menjadi, kata } \\
\text { dasar }\end{array}$ & $\begin{array}{c}\text { Kata depan: } \\
\text { di, ke, dari, } \\
\text { pada, kepada, } \\
\text { terhadap, } \\
\text { dengan, } \\
\text { untuk, dalam, } \\
\text { bagi, dll. }\end{array}$ \\
\hline
\end{tabular}

Agar lebih memahami peran storytelling di dalam DAD, pada penelitian ini dibuat dua narasi sebagai contoh simulasi pengerjaan storytelling antara lain sebagai berikut.

\section{Kasus 1:}

BAA (Biro Administrasi Akademik) mengumumkan daftar kelas kepada Mahasiswa. Kemudian Mahasiswa mengisi formulir KRS dan diberikan kepada Dosen Pembina. Dosen Pembina memeriksa berkas formulir KRS dan kemudian diberikan kepada BAA. BAA mencetak KRS dan diberikan kepada Mahasiswa.

\section{Kasus 2:}

Mahasiswa mengisi presensi daring dengan mengunduh materi kuliah yang terdapat pada aplikasi S, presensi tersebut kemudian diperiksa oleh Dosen. Jika ternyata ada beberapa mahasiswa gagal unduh dan melaporkannya kepada Dosen maka Dosen boleh mengisikan presensi untuk mahasiswa.

\section{HASIL DAN PEMBAHASAN}

Hasil

Kalimat pada kasus 1 disusun terlebih dahulu dengan pola kalimat bahasa Indonesia. BAA mengumumkan daftar kelas kepada mahasiswa selanjutnya mahasiswa mengisi dan memberikan formulir KRS kepada dosen pembina. Dosen pembina memeriksa dan memberikan berkas formulir KRS kepada BAA sehingga BAA akan mencetak dan memberikan KRS kepada mahasiswa. 
Selanjutnya, kalimat tersebut dipisahkan berdasarkan pola kalimat pada tabel 2. Hasil pemisahan disajikan pada tabel 3. Ketika pola kalimat sudah dibuat maka pola DAD dapat dibentuk. Pola DAD disusun berdasarkan kategori S, P, O, dan keterangan seperti gambar 1 .

Tabel 3. Pola Kalimat DAD Kasus 1

\begin{tabular}{|c|c|c|c|c|}
\hline Subjek (S) & Predikat (P) & Objek (O) & $\begin{array}{c}\text { Pelengkap } \\
\text { (Pel) }\end{array}$ & $\begin{array}{c}\text { Keterangan } \\
\text { (Ket) }\end{array}$ \\
\hline BAA & Mengumumkan & daftar kelas & - & $\begin{array}{c}\text { Kepada } \\
\text { Mahasiswa }\end{array}$ \\
\hline Mahasiswa & $\begin{array}{l}\text { mengisi, } \\
\text { memberikan }\end{array}$ & formulir KRS & - & $\begin{array}{c}\text { Kepada dosen } \\
\text { Pembina }\end{array}$ \\
\hline Dosen Pembina & $\begin{array}{l}\text { memeriksa, } \\
\text { memberikan }\end{array}$ & $\begin{array}{c}\text { berkas formulir } \\
\text { KRS }\end{array}$ & - & kepada BAA \\
\hline BAA & $\begin{array}{l}\text { mencetak, } \\
\text { memberikan }\end{array}$ & KRS & - & $\begin{array}{c}\text { Kepada } \\
\text { Mahasiswa }\end{array}$ \\
\hline
\end{tabular}

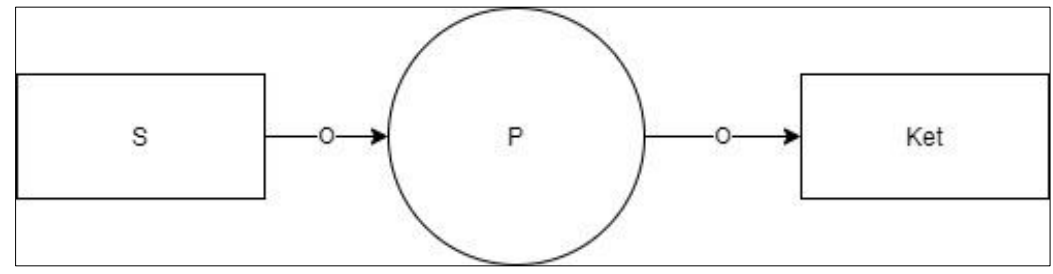

Gambar 1. Pola DAD Kasus 1

Berdasarkan gambar 1 ditemukan dua entitas yang berbeda, yakni entitas $\mathrm{S}$ dan entitas Ket. Entitas S dikaitkan ke proses $\mathrm{P}$ sehingga entitas tersebut adalah entitas sumber, sedangkan entitas Ket dikaitkan dari proses $\mathrm{P}$ sehingga disebut sebagai entitas tujuan. Selanjutnya, beberapa kata yang diperoleh dari tabel 3 dapat dikategorikan berdasarkan pola gambar 1 , antara lain entitas sumber (BAA, mahasiswa, dan dosen pembina), entitas tujuan (mahasiswa, dosen pembina, dan BAA), arus data (daftar kelas, formulir KRS, berkas formulir KRS, dan KRS), dan pada simbol proses di mana penulisan penamaan awalan me- diubah menjadi imbuhan pe-an seperti pengumuman, pengisian, pemberian, pemeriksaan, dan pencetakan. Penyusunan DAD yang dihasilkan seperti gambar 2.

Storyteling pada gambar 2, BAA mengumumkan daftar kelas kepada mahasiswa//Mahasiswa mengisi dan memberikan formulir KRS kepada dosen pembina//Dosen pembina memeriksa dan memberikan berkas formulir KRS kepada BAA//BAA mencetak dan memberikan KRS kepada mahasiswa. Namun, berbeda dengan kasus 2. Jika ada keterlibatan sistem, mengakibatkan banyaknya proses yang harus dihubungkan sehingga storytelling harus dibuat secara terperinci. Oleh sebab itu, penelitian ini membuat dua versi dalam penyusunan kalimat untuk dilihat perbedaannya. Rangkaian kata dibuat sebagai berikut.

Mahasiswa mengunduh materi kuliah. Jika gagal mengunduh materi kuliah di aplikasi S, mahasiswa mendapat notifikasi gagal. Jika mahasiswa berhasil mengunduh materi kuliah di aplikasi S, dosen mendapat notifikasi berhasil. Mahasiswa melaporkan kegagalan mengunduh materi kuliah kepada dosen. Dosen mengisi presensi mahasiswa sehingga mahasiswa mendapat notifikasi berhasil di aplikasi S. Langkah-langkah menyusun pola kalimat dan pembentukan pola DAD pada prinsipnya sama dengan tabel 3 dan gambar 1. Pola kalimat DAD kasus 2 dapat diamati pada tabel 4 . 


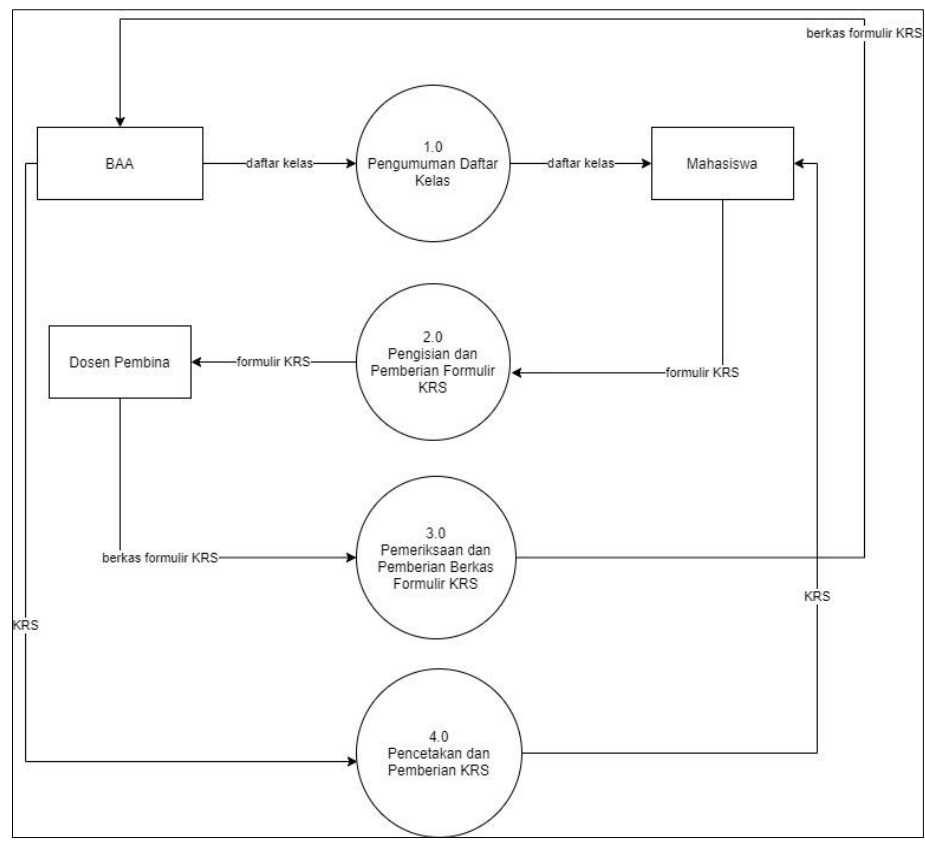

Gambar 2. DAD Kasus 1

Tabel 4. Pola Kalimat DAD Kasus 2

\begin{tabular}{ccccc}
\hline Subjek (S) & Predikat (P) & Objek (O) & $\begin{array}{c}\text { Pelengkap } \\
\text { (Pel) }\end{array}$ & $\begin{array}{c}\text { Keterangan } \\
\text { (Ket) }\end{array}$ \\
\hline $\begin{array}{c}\text { Mahasiswa } \\
\text { Mahasiswa }\end{array}$ & $\begin{array}{c}\text { Mengunduh } \\
\text { gagal } \\
\text { mengunduh; } \\
\text { mendapat } \\
\text { berhasil } \\
\text { mengunduh }\end{array}$ & $\begin{array}{c}\text { materi kuliah } \\
\text { materi kuliah; notifikasi } \\
\text { gagal }\end{array}$ & - & di aplikasi S \\
mahasiswa & Mendapat & notifikasi berhasil & - & di aplikasi S \\
DOSEN & Melaporkan & kegagalan mengunduh & $\begin{array}{c}\text { materi } \\
\text { kuliah }\end{array}$ & kepada dosen \\
Mahasiswa & mengisi; & $\begin{array}{c}\text { presensi mahasiswa; } \\
\text { notifikasi berhasil }\end{array}$ & - & di aplikasi S \\
Dosen; & Mendapat & - & - \\
\hline
\end{tabular}

Berdasarkan tabel 4, baris 1-3 mempunyai subjek yang sama secara berurutan seperti mahasiswa mengunduh materi kuliah, mahasiswa gagal mengunduh materi kuliah, mahasiswa mendapat notifikasi gagal, dan mahasiswa berhasil mengunduh materi kuliah sehingga memungkinkan membentuk beberapa proses yang saling berkorelasi. Oleh karena itu, pembentukan pola DAD menjadi seperti gambar 3. Selanjutnya, hasil rancangan DAD dapat dilihat pada gambar 4 yang mana proses $\mathrm{P} 1$ adalah proses $1.0, \mathrm{P} 2$ adalah proses 3.0, dan P3 adalah proses 2.0, sedangkan proses 4.0 dan 5.0 mengikuti pola DAD gambar 1 .

Storytelling versi 1 pada gambar 4: Mahasiswa mengunduh materi kuliah//Jika gagal mengunduh materi kuliah di aplikasi S, mahasiswa mendapat notifikasi gagal//Jika mahasiswa berhasil mengunduh materi kuliah di aplikasi $\mathrm{S}$, dosen mendapat notifikasi berhasil//Mahasiswa melapor gagal unduh materi kuliah kepada dosen//Dosen mengisi presensi mahasiswa sehingga mahasiswa mendapat notifikasi berhasil di aplikasi S. 


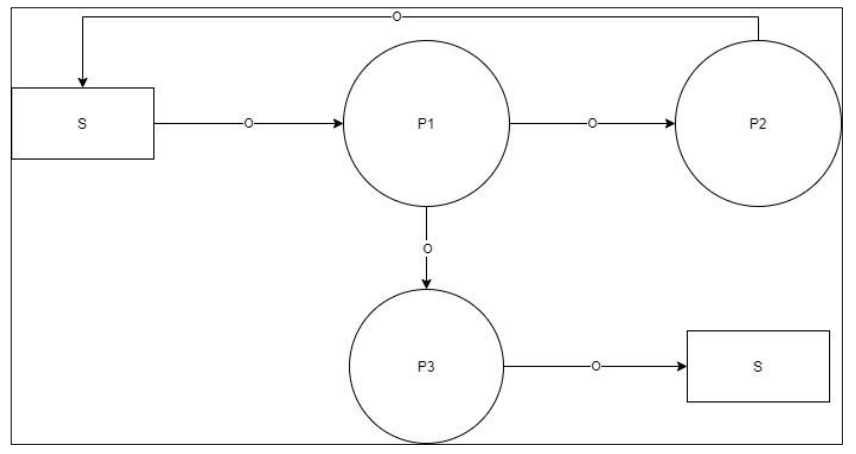

Gambar 3. Pola DAD Keterkaitan Banyak Proses

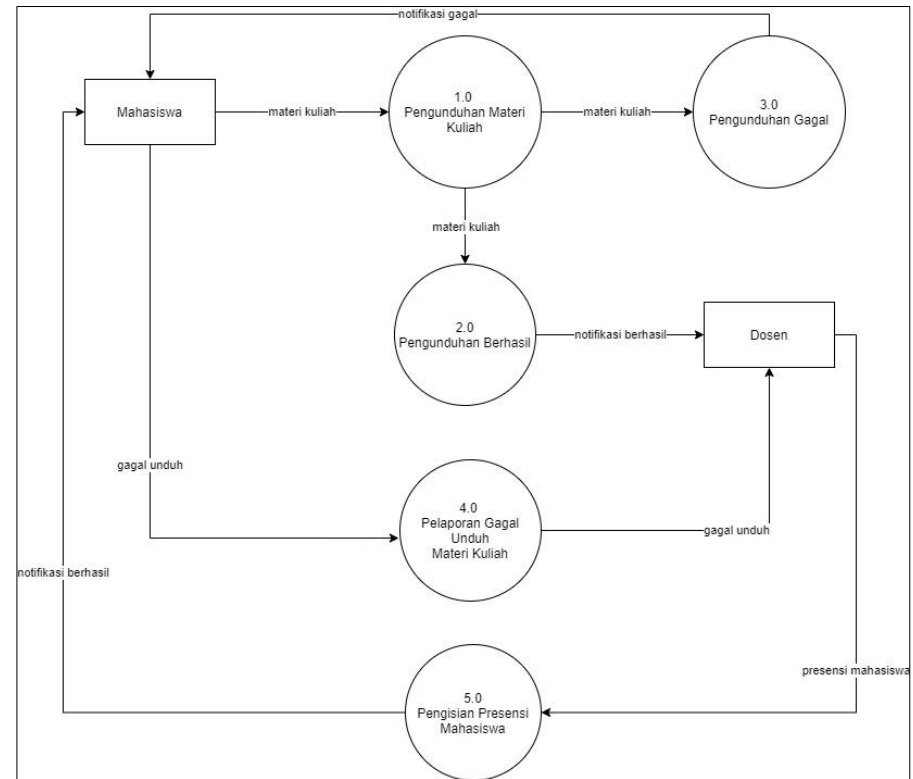

Gambar 4. DAD Kasus 2

Akan tetapi, jika pendesain merasa tidak sesuai dengan perspektifnya. Penambahan kalimat dapat dilakukan dengan tidak mengubah kalimat yang lain dengan menyelipkan beberapa kata untuk pola kalimat dalam tabel 4 . Hasilnya disajikan pada tabel 5.

Tabel 5. Sepenggalan Pola Kalimat DAD Kasus 2

\begin{tabular}{|c|c|c|c|c|}
\hline Subjek (S) & Predikat (P) & Objek (O) & $\begin{array}{l}\text { Pelengkap } \\
\text { (Pel) }\end{array}$ & $\begin{array}{c}\text { Keterangan } \\
\text { (Ket) }\end{array}$ \\
\hline Mahasiswa & $\begin{array}{l}\text { berhasil } \\
\text { mengunduh }\end{array}$ & materi kuliah & - & di aplikasi $S$ \\
\hline $\begin{array}{l}\text { Mahasiswa } \\
\text { dosen }\end{array}$ & $\begin{array}{c}\text { dapat mengisi } \\
\text { Mendapat }\end{array}$ & $\begin{array}{l}\text { presensi daring } \\
\text { notifikasi berhasil }\end{array}$ & $\begin{array}{l}- \\
-\end{array}$ & - \\
\hline
\end{tabular}

Berdasarkan tabel 5, penyusunan kalimat berubah menjadi: Jika (mahasiswa) (S) berhasil mengunduh (P3) materi kuliah (O) di aplikasi S (Ket), mahasiswa (S) dapat mengisi (P4) presensi daring $(\mathrm{O})$ dan dosen $(\mathrm{S})$ mendapat $(\mathrm{P})$ notifikasi berhasil $(\mathrm{O})$. P3 dan P4 merupakan Predikat $(\mathrm{P})$ untuk simbol proses DAD, sedangkan $\mathrm{S}$ dapat menjadi subjek baik pada entitas sumber maupun tujuan. Perubahan pola DAD disajikan pada gambar 5. 


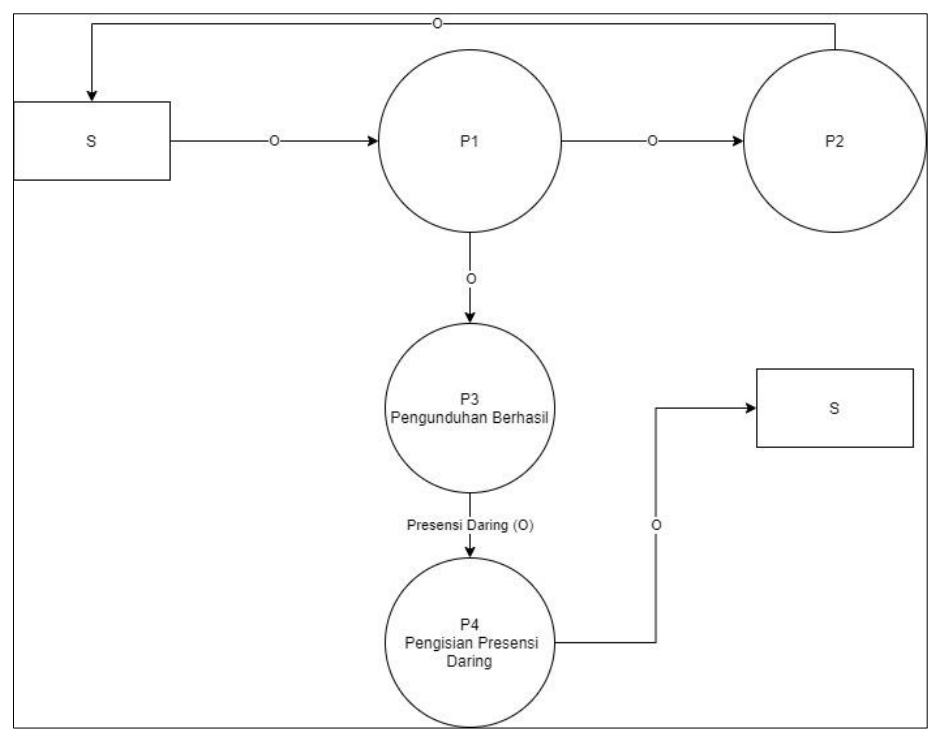

Gambar 5. Penambahan Simbol Proses DAD Kasus 2

Oleh karena itu, jika DAD kasus 2 pada gambar 4 disesuaikan dengan pola DAD pada gambar 5. Hasil storytelling versi 2 menjadi: Mahasiswa mengunduh materi kuliah//Jika gagal mengunduh materi kuliah di aplikasi S, mahasiswa mendapat notifikasi gagal//Jika mahasiswa berhasil mengunduh materi kuliah di aplikasi S, mahasiswa dapat mengisi presensi daring dan dosen mendapat notifikasi berhasil//Mahasiswa melapor gagal unduh materi kuliah kepada dosen//Dosen mengisi presensi mahasiswa sehingga mahasiswa mendapat notifikasi berhasil di aplikasi S

\section{Pembahasan}

Perancangan DAD pada penelitian ini dibuat menjadi dua jenis, yakni DAD berdasarkan sistem yang dipengaruhi oleh pengguna sistem dan dipengaruhi kinerja perangkat lunak. Jika dipengaruhi oleh pengguna sistem maka akan banyak simbol entitas yang dibuat. Sebaliknya, jika dipengaruhi oleh kinerja perangkat lunak maka banyak simbol proses yang digunakan. Kasus 1 dibuat berdasarkan pengaruh pengguna sistem yang di mana kinerja perangkat lunak tidak banyak terlihat. Pola DAD pada gambar 1 mengacu pada konsep dasar input-prosesoutput, di mana input merupakan entitas sumber yang mana sebagai Subjek (S), proses sebagai Predikat (P), dan output merupakan entitas tujuan sebagai Keterangan (Ket). Entitas tersebut dapat berupa sekelompok orang, perusahaan, devisi, dan organisasi. Entitas tersebut termasuk kategori Subjek. Namun, jika berdasarkan pola DAD maka entitas yang dikatakan subjek mengacu pada entitas yang memberikan input ke proses, sedangkan keterangan mengacu pada entitas yang menerima output dari proses. Entitas yang memberikan input dan menerima output didasari arah panah arus data, di mana arus data dikatakan objek yang berisi data atau informasi. Di samping itu, aktivitas sistem hanya terjadi pada proses sehingga penamaan diberikan imbuhan pe-an untuk mewakili bagaimana proses sistem bekerja.

Storytelling pada kasus 1 lebih konsisten karena pola DAD dan S-P-O-Ket di dalamnya tidak mengalami perubahan signifikan. Pembuktian dapat dilihat dengan membandingkan gambar 1 dan 2 untuk setiap penomoran proses, perancangannya menjadi lebih mudah dibuat. Oleh sebab itu, beberapa penelitian seperti (Afuan et al., 2021; Reforma et al., 2021; Rohimah \& Kustian, 2021; Wibowo et al., 2014) menggunakan pola DAD gambar 1. Selain mudah dibuat perancangan diagram, pola DAD tersebut mampu menelusuri ketidaksesuaian storytelling yang diakibatkan blackhole, miracle, dan tidak lengkapnya proses input-output (Afuan et al., 2021; Reforma et al., 2021; Wibowo et al., 2014). Oleh karena itu, pendesain dapat memahami notasi mana yang belum dibuat dalam perancangan DAD. Sebaliknya, 
penelitian (Rohimah \& Kustian, 2021) sesuai dengan pola DAD, tetapi beberapa penamaan arus data dan proses tidak sesuai dengan S-P-O-Ket. Namun, secara keseluruhan storytelling masih dapat diinterpretasikan.

Berbeda dengan kasus 2, di mana fokus kepada kinerja perangkat lunak. Akibatnya banyak proses yang dilakukan dengan mengaitkan simbol proses ke proses. Tidak seperti pada kasus 1 yang mana kolom keterangan pada tabel 3 terisi semua, sedangkan kasus 2 pada tabel 4 lebih banyak mengisi kolom subjek. Jika hanya mengacu pada pola kalimat S-P-O-Ket maka pola DAD tidak dapat dibuat. Oleh sebab itu, penelitian ini dilakukan analisis lanjut pada penyusunan kalimat. Rangkaian kalimat di dalam storytelling kasus 2 ditemukan penyeleksian kondisi sehingga kalimat yang disusun merupakan kalimat lanjutan. Akibatnya, entitas dikategorikan ke dalam subjek baik entitas sumber dan tujuan. Di samping itu, pernyataan kondisi menghasilkan dua tindakan yang bernilai benar dan salah yang menyebabkan simbol proses terbagi menjadi dua cabang, yakni proses yang bernilai benar (berhasil mengunduh) dan salah (gagal mengunduh). Selanjutnya, beberapa kategori pola kalimat kasus 2 pada tabel 4 tidak digunakan karena mempertimbangkan susunan kalimat yang mengakibatkan pola DAD menjadi kompleks. Oleh karena itu, perancangan DAD dengan model kasus 2 jarang digunakan pada penelitian nasional. Walaupun demikian, pola DAD yang dibuat dari storytelling kasus 2 dapat sebagai landasan dasar dalam pemenuhan kebutuhan perangkat lunak. Sebagai kesimpulan, pola DAD pada kasus 2 sesuai dengan elisitasi kebutuhan (Hathaway \& Hathaway, 2015), dan kasus 1 mengacu pada proses bisnis.

\section{SIMPULAN}

Berdasarkan dua kasus yang dibuat untuk perancangan DAD, terdapat dua disparitas yang signifikan. Kasus 1 mengacu pada aktivitas pengguna sistem dan kasus 2 merujuk ke kinerja perangkat lunak. Hasil olahan dibuat dari pola kalimat ke pola DAD, storytelling kasus 1 lebih konsisten dan mudah dibuat perancangannya karena mengacu pada konsep dasar inputproses-output. Oleh karena itu, penelitian terdahulu merujuk pada pola DAD kasus 1. Selain itu, kesalahan diakibatkan blackhole, miracle, dan tidak lengkapnya input-output dapat ditelusuri. Selanjutnya, Kasus 1 lebih mengacu pada proses bisnis karena berbasis dengan aktivitas pengguna yang berinteraksi terhadap sistem. Berbeda dengan kasus 2, banyak mengaitkan simbol proses ke proses sehingga pembuatan rancangan DAD semakin kompleks. Adanya pernyataan kondisi mengakibatkan analisis lanjut dengan tidak hanya mempertimbangkan pola kalimat. Namun, merujuk pada susunan kalimat sehingga mendapatkan pola DAD yang tepat. Oleh sebab itu, storytelling pada kasus 2 dapat digunakan untuk elisitasi kebutuhan perangkat lunak.

\section{REFERENSI}

Afuan, L., Nofiyati, N., \& Umayah, N. (2021). Rancang Bangun Sistem Informasi Bank Sampah di Desa Paguyangan. Edumatic: Jurnal Pendidikan Informatika, 5(1), 21-30.

Aleryani, A. Y. (2016). Comparative Study between Data Flow Diagram and Use Case Diagram. International Journal of Scientific and Research Publications, 6(3), 124-127.

Ambarsari, E. W., \& Herlinda, H. (2020). Pythagoras Tree Applied For Determined Instagram Usage Habit Decision. SinkrOn, 4(2), 56-61. https://doi.org/10.33395/sinkron.v4i2.10517

Gürsoy, G. (2021). Digital storytelling: Developing 21st century skills in science education. European Journal of Educational Research, 10(1), 97-113. https://doi.org/10.12973/EUJER.10.1.97

Hathaway, T., \& Hathaway, A. (2015). Data Flow Diagramming by Example: Process Modeling Techniques for Requirements Elicitation. BA-Experts.

Hidayat, D. B., Muktadir, A. M., \& Dharmayana, I. W. (2019). Efektivitas Metode 
Mendongeng (Storytelling) dalam Meningkatkan Keterampilan Berbicara dan Keterampilan Membaca Siswa (Sebuah Studi Kasus di SDN 55 Bengkulu Selatan). Jurnal Pembelajaran Dan Pengajaran Pendidikan Dasar, 2(2), 120-128. https://doi.org/10.33369/dikdas.v2i2.10582

Kim, Y., \& Hartanto, A. (2020). Storytelling in clothing design: A study of fashion brand "SEAM" in Indonesia. International Journal of Scientific and Technology Research, 9(1), 914-919.

Knaflic, C. N. (2015). Storytelling with Data: A Data Visualization Guide for Business Professionals. John Wiley \& Sons, Inc.

Kusuma, T. M. J. (2007). Pengantar (Metode) Penelitian Bahasa. Yogyakarta: Balai Pustaka. Lundqvist, A., Liljander, V., Gummerus, J., \& van Riel, A. (2013). The impact of storytelling on the consumer brand experience: The case of a firm-originated story. Journal of Brand Management, 20(4), 283-297. https://doi.org/10.1057/bm.2012.15

Matei, S. A., \& Hunter, L. (2021). Data storytelling is not storytelling with data: A framework for storytelling in science communication and data journalism. Information Society, 37(5), 312-322. https://doi.org/10.1080/01972243.2021.1951415

Moeliono, A. M., Lapoliwa, H., Alwi, H., Wisnu Sasangka, S. S. T., \& Sugiyono. (2017). Tata Bahasa Baku Bahasa Indonesia (fourth). Badan Pengembangan dan Pembinaan Bahasa. Kementerian Pendidikan dan Kebudayaan.

Muntohar, A. (2020). Sistem Informasi Data Klien Berbasis Java Pada Kantor Notaris dan PPAT Arif. Edumatic: Jurnal Pendidikan Informatika, 4(2), 58-67. https://doi.org/10.29408/edumatic.v4i2.2515

Pratiwi, R. (2016). Penerapan Metode Storytelling Untuk Meningkatkan Keterampilan Berbicara Siswa Kelas II SDN S4 Bandung. Jurnal Pendidikan Guru Sekolah Dasar, 1(1), 199-207. https://doi.org/10.17509/jpgsd.v1i1.9074

Reforma, N., Basir, R. R., \& Theodora, B. D. (2021). Rancang Bangun Aplikasi Akademik Berbasis Java pada SMK Prestasi Prima. Jurnal Riset Dan Aplikasi Mahasiswa Informatika (JRAMI), 2(03), 551-558. https://doi.org/10.30998/jrami.v2i03.1534

Rohimah, I., \& Kustian, N. (2021). Sistem Informasi Pengelolaan Keluhan Pelanggan pada Toko Kain Flanel Jakarta Timur. Jurnal Riset Dan Aplikasi Mahasiswa Informatika (JRAMI), 2(03), 536-543. https://doi.org/10.30998/jrami.v2i03.1220

Sakti, R. H., Sukardi, S., Giatman, M., Nazar, E., Wakhinuddin, W., \& Waskito, W. (2020). Flipped Classroom-Computer Based Instruction untuk Pembelajaran Pada Revolusi Industri 4.0: Rancang Bangun dan Analisis Kebutuhan. Edumatic: Jurnal Pendidikan Informatika, 4(1), 63-72.

Satriani, I. (2019). Storytelling in Teaching Literacy: Benefits and Challenges. English Review: Journal of English Education, 8(1), 113-120. https://doi.org/10.25134/erjee.v8i1.1924

Septianingtias, V. (2015). Pola kalimat pada kumpulan dongeng gadis korek api karya H.C. Andersen (suatu kajian sintaksis). Jurnal Pesona, 1(1), 42-49.

Soufitri, F. (2019). Perancangan Data Flow Diagram Untuk Sistem Informasi Sekolah (Studi Kasus Pada Smp Plus Terpadu). Ready Star, 2(1), 240-246.

Wibowo, G. I., Rumagit, A. M., \& Tuturoong, N. J. (2014). Perancangan Aplikasi Gudang Pada Pt. Pakan Ternak Sejati. Jurnal Teknik Elektro Dan Komputer, 3(4), 11-18. 